
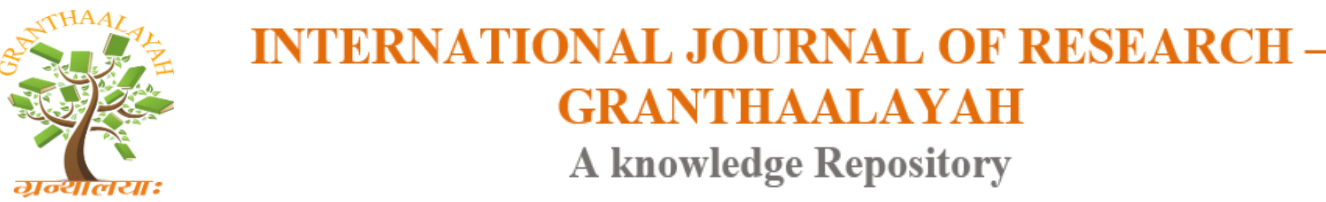

Science

\title{
ENDOSCOPIC PICTURE OF FALLOPIAN TUBES STATE IN KAZAKHSTAN WOMEN WITH NATURAL STERILITY COMBINED WITH REPRODUCTIVE DISEASES
}

\author{
Aketaeva Asem Sagimbekovna ${ }^{1}$, Smailova Lazat Kenzhebekovna ${ }^{1}$, Kabikenova Dinara \\ Kenzhetaevna ${ }^{1}$ \\ ${ }^{1}$ JSC «Medical University Astana», Department of Obstetrics and Gynecology Internship \\ Astana City, Republic of Kazakhstan
}

\begin{abstract}
Determination of level of fallopian tube affect and assessment of fallopian tube state in women with natural sterility combined with reproductive diseases.

The analysis of endoscopic surgery results was presented by sampling in 200 patients, of which 98 patients with natural sterility, 102 with secondary sterility.

The patients with natural sterility were distributed by three groups:

1 group was made up with patients with natural sterility combined with endometriosis $(n=33)$,

2 made up with patients with natural sterility combined with uterine fibroid $(n=26)$,

3 are patients with natural sterility combined with chronic salpingitis.

All patients have passed the standard examination.

According to data of sonographic hydrotubation in 1 group the double-sided uterine tubes patency was observed in $28 \%(84,85+6,24)$, in 2 group in $20 \%(76,92+8,26)$, in 3 group 29 $\%(74,36+6,99)$ of cases.

Under laparoscopic examination of fallopian tube the changes were observed in 1 group in $10 \%$ $(30,30+8,00)$ of cases. In 2 group the changes are observed in $20 \%(76,92+8,26)$ of cases. In 3 group the changes are observed in $32 \%(82,05+6,15)$ of cases.

Hereby in view of the presence of patients with natural sterility the frequency of fallopian tube abnormality in three groups was equal from $30 \%$ to $82,05 \%$, despite its double-sided patency $74,36 \%$ to $84,85 \%$. Therefore the endoscopic interventions shall be performed not with the purpose of diagnosis verification but with medical purpose.
\end{abstract}

Keywords: Female Sterility; Endometriosis; Uterine Fibroid; Chronic Salpingitis; Fallopian Tube.

Cite This Article: Aketaeva Asem Sagimbekovna, Smailova Lazat Kenzhebekovna, and Kabikenova Dinara Kenzhetaevna. (2017). "ENDOSCOPIC PICTURE OF FALLOPIAN TUBES STATE IN KAZAKHSTAN WOMEN WITH NATURAL STERILITY COMBINED WITH REPRODUCTIVE DISEASES." International Journal of Research - Granthaalayah, 5(8), 94-103. https://doi.org/10.29121/granthaalayah.v5.i8.2017.2188. 


\section{Introduction}

Relevance: The problem of female infertility remains one of the most urgent problems in modern gynecological practice $[1,2,3,4,5]$.

The leading form of female infertility, found among all forms of infertility, is the tubularperitoneal form. The cause of tubal-peritoneal form of infertility is inflammation of the pelvic organs $[6,7,8]$.

The cause of the fallopian tubes injury can be not only the inflammation of the pelvis, but also other major diseases of the pelvic organs (endometriosis, uterine myoma). With uterine myoma, either mechanical compression of the fallopian tubes occurs, or their functional state is disrupted. Obstruction of the fallopian tubes due to endometriosis occurs in 10-15\% of cases [9].

Fallopian tubes are of great importance in the process of fertilization, transporting gametes and embryos. Therefore, evaluation of the condition of the fallopian tubes is extremely important in the investigation of female infertility and is mandatory before using assisted reproductive technologies (ART), namely, intrauterine insemination and in vitro fertilization [10].

Advancements in the field of medicine made it possible to raise medical assistance to patients with female infertility to a fundamentally new level. This became possible due to the application of the newest methods of examination, namely endoscopic methods using modern technical means $[11,12]$.

In order to diagnose the anatomical and functional state of the fallopian tubes in infertility, laparoscopic methods of investigation are widely used. For example, in the recognition of salpingitis before the laparoscopic operation, the diagnostic error was $20.4 \%$, with overdiagnosis- $8.2 \%$, and an insufficient assessment of salpingitis-12.2\%. In laparoscopic examination, the following signs of chronic salpingitis were found: injection of the fallopian tubes $(60.4 \%)$, constrictions $(2.3 \%)$, thickening of the fallopian tubes $(1.2 \%)[13,14,15]$.

In this regard, the issue of diagnosing the state of the fallopian tubes is of particular importance. During endoscopy, namely laparoscopy, the status of the uterus, ovaries and fallopian tubes, pictures of acute and chronic inflammation of the uterine appendages, endometriosis, uterine fibroids, which require appropriate treatment, are assessed.

\section{Objective of Research}

Determination of level of fallopian tube affect and assessment of fallopian tube state in women with natural sterility combined with reproductive diseases.

\section{Materials and Research Methods}

This research was performed in gynecology department of the Perinatal center №1 of Astana city (Kazakhstan) over a period from 2014 to 2016. 200 patients, of which 98 with natural sterility, 102 with secondary sterility were examined by us. 
The patients with natural sterility were distributed for three groups:

1 group was made up with the patients with natural sterility combined with endometriosis $(n=33)$,

2 made up with the patients with natural fertility combined with uterine fibroid $(n=26)$,

3 with natural sterility combined with chronic salpingitis.

The age of examined patients in 1 group has ranged within 24 to 41 years, average age was equal to $32,39 \pm 4,81$ years

The age of examined patients in 2 group has ranged within 24 to 46 years and older, average age was equal to $35,8+4,75$ years.

The age of examined patients in 3 group has ranged within 24 to 45 and older, average age was equal to $31,97 \pm 4,89$ years.

All patients have passed the routine examination; exclusionary criteria consist of the presence of OPS (polycystic ovarian syndrome) and male factor infertility.

The obtained data were statistically processed on individual computer using the «Microsoft Excel» spreadsheets and «SPSS Statistics» application program package.

Outcome: Age of onset of menarche in 1 group was ranged within 12 to 16 and older (Table 1).

Table 1: Average age of offensive menstrual functions

\begin{tabular}{|l|l|l|l|}
\hline \multicolumn{1}{|c|}{ Parameter } & \multicolumn{1}{c|}{$\begin{array}{c}\text { Group 1 } \\
\mathbf{n = 3 3}(\mathbf{M} \pm \mathbf{m})\end{array}$} & $\begin{array}{c}\text { Group 2 } \\
\mathbf{n = 2 6}(\mathbf{M} \pm \mathbf{m})\end{array}$ & \multicolumn{1}{c|}{$\begin{array}{c}\text { Group 3 } \\
\mathbf{n = 3 9}(\mathbf{M} \pm \mathbf{m})\end{array}$} \\
\hline Age & & & \\
\hline $12-14$ & $13,2 \pm 0,93$ years & $13,13 \pm 0,69$ years & $13,12 \pm 0,72$ years \\
\hline $15-16$ & $15,6 \underline{ \pm 0,47 \text { years }}$ & $15,75 \underline{ \pm 0,43}$ years & $16 \pm 0,0$ years \\
\hline 16 years and more & - & - & - \\
\hline
\end{tabular}

According to Table1 the average menarche age was equal to $13,57 \pm 1,30$ years. Age of onset of menarche in 2 group was ranged within 12 to 16 years. The average menarche age was equal to $13,53 \pm 1,15$ лет. Age of onset of menarche in 3 group was ranged within 12 to 16 years and older, average age- $13,56 \pm 1,23$ years.

The timely menarche (at the age from 12 to 16 years) was observed in majority of women in all groups.

The duration of menstrual bleeding from 3 to 7 days in three groups and on average were equal in 1 group to $5,39 \pm 0,88$ days, in 2 group $5,39 \pm 0,89$ days, in 3 group $4,82 \pm 1,15$ days. The duration of menstrual cycle was equal in 1 group to $28,4 \pm 2,79$ days, 2 group $28,42 \pm 2,7$ days, in 3 group 29,48 $\pm 5,23$ days.

With characteristics of menstrual disorders of women examined in 1 group the menstrual abnormality was observed in $16 \%(48,48 \pm 8,70)$, at that by hyperpolymenorrhea type in $2 \%$ 
$(6,06 \pm 4,15)$ of cases, by dysmenorrhea type $6 \%(18,18 \pm 6,71)$, by type of pre- and postmenstrual bloody flux in $3 \%(9,09 \pm 5,00)$, by opsomenorrhea type in $2 \%(6,06 \pm 4,15)$.

In 2 group the menstrual abnormality was observed in $10 \%(38,46 \pm 9,54)$ of patients, at that by hyperpolymenorrhea type in $4 \%(15,38 \pm 7,08)$, by dysmenorrhea type $4 \%(15,38 \pm 7,08)$, by type of pre- and postmenstrual bloody flux in $3 \%(9,09 \pm 5,00)$, by opsomenorrhea type in $2 \%$ $(7,69 \pm 5,23)$. In 3 group the menstrual abnormality was observed in $4 \%(10,26 \pm 4,86)$ of patients, at that by dysmenorrhea type $2 \%(5,13 \pm 3,53)$, by opsomenorrhea type in $2 \%(5,13 \pm 3,53)$.

The data analysis has shown that the distinctions between the groups are statistically valid by Fisher's exact test $(p=0,10)$ at $(p<0,05)$, By this attribute the groups appeared to be comparable.

\section{Genital Function}

The sex life in 1 group of examined women from 16 to 27 years.

The sex life on average was equal to $20,69 \pm 2,90$ years.

The sex life in 2 group of examined women from 17 to 37 years.

The sex life on average was equal to $23,07 \pm 5,06$ years.

The sex life in 3 group of examined women from 17 to 27 years.

The sex life on average was equal to $20,56 \pm 2,73$ years.

\section{Reproductive Function}

The patients of 1 group have noted the absence of pregnancy within 1 to 16 years with regular sex life. The natural sterility has taken place in 33 women. The duration of natural sterility was equal on average to $3,5 \pm 2,3$ years. The patients of 2 group have noted the absence of pregnancy within 1,0 to 14 years with regular sex life. The natural sterility has taken place in 26 women. The duration of natural sterility was equal on average to $4,28 \pm 3,3$ years.

The patients of 3 group have noted the absence of pregnancy within 1,0 to 17 years with regular sex life. The natural sterility has taken place in 39 women. The duration of natural sterility was equal on average to $5,12 \pm 3,76$ years.

By frequency of extragenital diseases at examined women of 1 group the diseases of respiratory system was in $2 \%(6,06 \pm 4,15)$, digestive apparatus in $3 \%(9,09 \pm 5,00)$ of cases, urinary system in $1 \%(3,03 \pm 2,98)$, diseases of endocrine system in $3 \%(9,09 \pm 5,00)$, adiposis in $1 \%(3,03 \pm 2,98)$. In 2 group diseases of respiratory system was in $1 \%(3,85 \pm 3,77)$ of cases, digestive apparatus in $1 \%$ $(3,85 \pm 3,77)$, cardiovascular system in $1 \%(3,85 \pm 3,77)$, diseases of endocrine system in $2 \%$ $(7,69 \pm 5,23)$, adiposis in $1 \%(3,85 \pm 3,77)$. In 3 group the diseases of respiratory system was in $1 \%(2,56 \pm 2,53)$, digestive apparatus in $2 \%(5,13 \pm 3,53)$, urinary system in $2 \%(5,13 \pm 3,53)$, diseases of endocrine system in $6 \%(15,38+5,78)$, adiposis in $2 \%(5,13 \pm 3,53)$ of cases.

The analysis of frequency of associated extragenital abnormality in examined groups has shown that the most frequently detectable abnormality in patients with natural sterility combined with chronic salpingitis are the diseases of endocrine system (thyroid disorders $-15,38 \%$ ). By other attributes there were no statistical discrepancy in Fisher $(p=0,42)$ at $(p<0,05)$. 
In the pattern of associated gynecological abnormality in 1 group $5 \%$ have an endometrium abnormality $(15,15 \pm 6,24)$, oothecoma $6 \%(18,18+6,71)$, endometriosis $5 \%(15,15 \pm 6,24)$, fallopian tube abnormity in $5 \%(15,15 \pm 6,24)$, cervical ectropion was in $4 \%(12,12 \pm 5,68)$, adhesive process in $3 \%(9,09+5,00)$, as well as sexually-transmitted infections in $5 \%$ $(15,15 \pm 6,24)$ of patients.

In 2 group there are endometrium abnormality $1 \%(3,85 \pm 3,77)$, oothecoma $2 \%(7,69 \pm 5,23)$, endometriosis $1 \%(3,85 \pm 3,77)$, fallopian tube abnormity in $6 \%(23,08 \pm 8,26)$, cervical ectropion was in $3 \%(11,54 \pm 6,27)$, adhesive process in $2 \%(7,69+5,23)$, as well as sexually-transmitted infections in $1 \%(3,85 \pm 3,77)$ of patients.

In 3 there are endometrium abnormality $3 \%(7,69 \pm 4,27)$, oothecoma $3 \%(7,69 \pm 4,27)$, endometriosis $1 \%(2,56 \pm 2,53)$, hydrosalpynx $4 \%(10,26 \pm 4,86)$, cervical ectropion was in $3 \%$ $(10,26+4,86)$, adhesive process in $8 \%(20,51 \pm 6,47)$ as well as sexually-transmitted infections in $13 \%(33,33 \pm 7,55)$ of patients.

The analysis of associated gynecological disorders has shown that in Fisher $\mathrm{p}=0,13$ at $(\mathrm{p}<0,05)$.

The cystectomy in $1 \%(3,85 \pm 3,77)$, abdominoscopy, salpingoneostomy in $1 \%(3,03 \pm 2,98)$, hysteroscopy, polypectomy in $3 \%(9,09 \pm 5,00)$ of cases were among the surgical service in anamnesis of 1 group.

The appendectomy in $5 \%(15 \pm 6,24)$, cystectomy in $4 \%(12 \pm 5,68)$, abdominoscopy, salpingoneostomy in $2 \%(7,69 \pm 5,23)$, tubectomy in $2 \%(7,69 \pm 5,23)$, ovariectomy in $1 \%$ $(3,85 \pm 3,77)$, cholecystectomy in $1 \%(3,85 \pm 3,77)$ of cases was in 2 group.

The appendectomy in $4 \%(10,26 \pm 4,86)$, cystectomy in $6 \%(15 \pm 5,78)$, abdominoscopy, salpingoneostomy in $1 \%(2,56 \pm 2,53)$, hysteroscopy, polypectomy in $1 \%(2,56 \pm 2,53)$, tubectomy in $3 \%(7,69 \pm 4,27)$, ovariectomy in $1 \%(2,56 \pm 2,53)$, cholecystectomy in $1 \%(2,56 \pm 2,53)$ of cases was in 3 group.

In such a manner by attributes of surgical service the statistical analysis has shown that according to Fisher $\mathrm{p}=0,30$ at $(\mathrm{p}<0,05)$.

During carrying out of ultrasound investigation of lower pelvis we have detected in 1 group the oothecoma in $17 \%(51,52 \pm 8,70)$, adenomyosis in $1 \%(3,03 \pm 2,98)$, hydrosalpinx $1 \%(3,03 \pm 2,98)$, uterine fibroid in $1 \%(3,03 \pm 2,98)$, chronic salpingitis in $3 \%(9,09 \pm 5,00)$, endometrium abnormality in $2 \%(6,06 \pm 4,15)$, adhesive process in $1 \%(3,85 \pm 3,77)$ of cases.

In 2 group the oothecoma in $2 \%(7,69 \pm 5,23)$, adenomyosis in $1 \%(3,85 \pm 3,77)$, uterine fibroid in $6 \%(23,08 \pm 8,26)$, chronic salpingitis in $3 \%(3,85 \pm 3,77)$, endometrium abnormality in $3 \%$ $(11,54 \pm 6,27)$ of cases.

In 3 group the oothecoma in $4 \%(10,26 \pm 4,86)$, adenomyosis in $2 \%(5,13 \pm 3,53)$, chronic salpingitis in $7 \%(17,95 \pm 6,15)$, endometrium abnormality in $5 \%(12 \pm 5,35)$, adhesive process in $4 \%(10,26 \pm 4,86)$ of cases. 
The analysis of obtained data has shown that according to Fisher $p=0,82$ at $(p<0,05)$.

According to data the uterotubograhy is presented in women examined in compared groups (Fig.1).

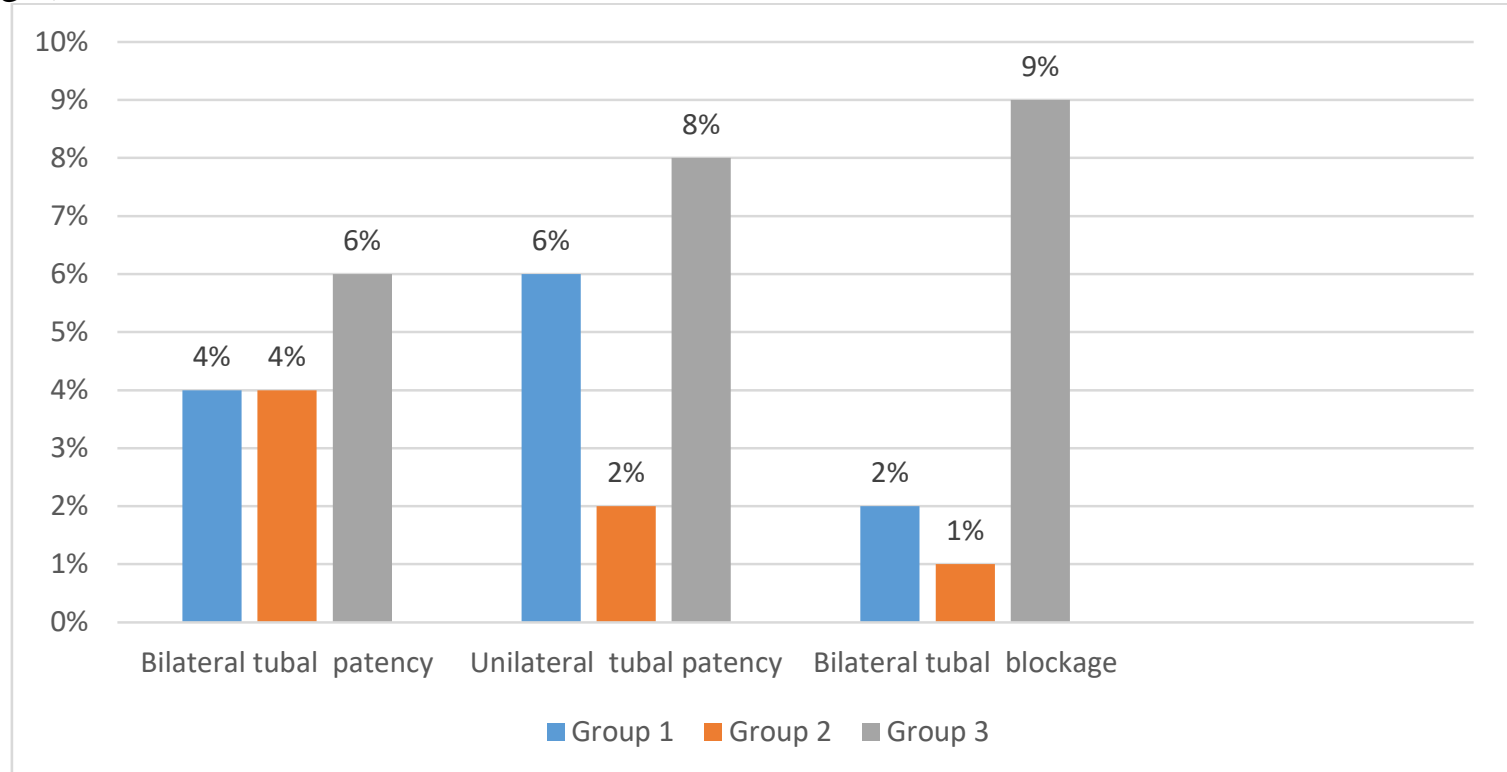

Figure 1: Characteristics of tubal patency according to the data of the examined women's hysterosalpingography (HSG).

The data analysis has shown that according to Fisher at $\mathrm{p}=0,22$ at $(\mathrm{p}<0,05)$ there were no any statistical discrepancy.

According to data of sonographic hydrotubation in examined women in compared groups is presented in (Fig.2).

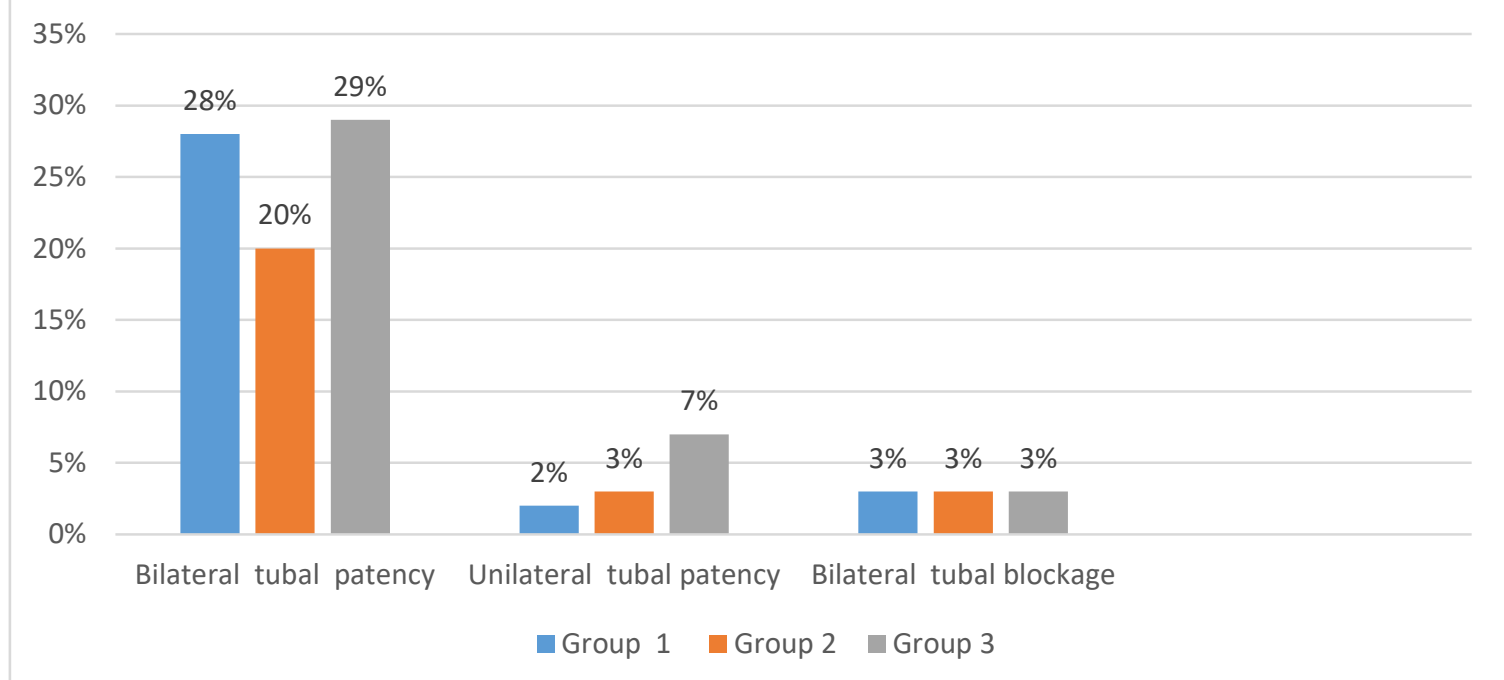

Figure 2: Characteristics of tubal patency on the basis of the data of sonographic hydrotubation of the examined women. 
According to data of three groups during comparison by one-way ANOVA was equal by Bonferroni $\mathrm{p}=1,0$; by Scheffe $\mathrm{p}=0,97$; by Tukey $\mathrm{p}=0,97$, at $(\mathrm{p}<0,05)$, that has shown that there are no significant differences between the groups.

In 1 group the ampular section of tube was in $2 \%(6,06 \pm 4,15)$ of cases under one-sided tubal obstruction and distribution of obstruction, the isthmic section of pipe was an obstruction location under double-sided tubal obstruction in $1 \%(3,03 \pm 2,98)$ and ampular section in $2 \%$ $(6,06+4,15)$ of cases.

In 2 group the isthmic section of tube was an obstruction place under one-sided tubal obstruction in $2 \%(7,69 \pm 5,23)$ and ampular section in $3 \%(11,54 \pm 6,27)$ of cases, under doublesided tubal obstruction the isthmic section of pipe was an obstruction location in $1 \%(3,85 \pm 3,77)$ and ampular section in $2 \%(7,69 \pm 5,23)$ of cases.

In 3 group under one-sided tubal obstruction the isthmic section of pipe was an obstruction location in $3 \%(7,69 \pm 4,27)$ and ampular section in $4 \%(10,26 \pm 4,86)$ of cases, under double-sided tubal obstruction the isthmic section of pipe was an obstruction location in $1 \%(2,56 \pm 2,53)$ and ampular section in $2 \%(5,13 \pm 3,53)$ of cases.

The detected abnormality of pelvic organs during abdominoscopy in examined patients:

1 group:- endometriotic heterotropy in uterovesical spatium were in $3 \%(9,09 \pm 5,00)$, endometriotic heterotropy on sacro-uterine ligament in $5 \%(15,15 \pm 6,24)$, endometriotic heterotropy on lower pelvis serosa in $4 \%(12,12 \pm 5,68)$, endometriotic heterotropy in retrouterine spatium in $3 \%(9,09 \pm 5,00)$, endometriodic foci on ovarian surface in $4 \%(12,12 \pm 5,68)$, endometriodic cystic lesion in $18 \%(54,55 \pm 8,67)$, adenomyosis in $5 \%(15,15 \pm 6,24)$, uterine fibroid in $1 \%(3,03 \pm 2,98)$, hydrosalpynx in $1 \%(3,03 \pm 2,98)$, chronic salpingitis in $1 \%$ $(3,03 \pm 2,98)$, agenesia of fallopian tube and ootheca in $1 \%(3,03 \pm 2,98)$, adhesive process in $4 \%$ $(12,12 \pm 5,68)$ of cases.

2 group:- endometriotic heterotropy on sacro-uterine ligament in $1 \%(3,85 \pm 3,77)$, oothecoma in $3 \%(11,54 \pm 6,27)$, hydrosalpynx in $3 \%(11,54 \pm 6,27)$, bicomuate uterus in $1 \%(3,85 \pm 3,77)$, adhesive process in $3 \%(11,54 \pm 6,27$ of cases.

3 group:- endometriotic heterotropy on sacro-uterine ligament in $2 \%(5,13 \pm 3,53)$, oothecoma in $2 \%(5,13 \pm 3,53)$, hydrosalpynx in $3 \%(7,69 \pm 4,27)$, bicomuate uterus in $1 \%(3,85 \pm 3,77)$ adhesive process in $8 \%(20,51 \pm 6,47)$ of cases.

The scope of surgical intervention during diagnostic and treatment abdominoscopy conducted in examined patients is shown in the Table 2 . 
Table 2: Surgical measures volume when perform diagnostic and treatment laparoscopy of the examined patients

\begin{tabular}{|c|c|c|c|c|c|c|c|}
\hline № & $\begin{array}{l}\text { Medical procedure } \\
\text { name }\end{array}$ & & $\begin{array}{c}\text { Group 1 } \\
M \pm m \\
\mathbf{n}=33\end{array}$ & & $\begin{array}{c}\text { Group 2 } \\
M \pm m \\
n=26\end{array}$ & & 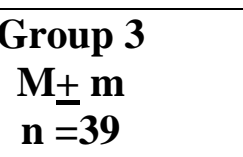 \\
\hline 1 & $\begin{array}{l}\text { Laser } \\
\text { photocoagulation of } \\
\text { focus of } \\
\text { endometrioid } \\
\text { heterotopia of } \\
\text { peritoneum }\end{array}$ & $4 \%$ & $(12,12 \pm 5,68)$ & - & - & - & - \\
\hline 2 & $\begin{array}{l}\text { Laser } \\
\text { photocoagulation of } \\
\text { focus of posterior } \\
\text { Cul-de-Sac }\end{array}$ & $3 \%$ & $(9,09 \pm 5,00)$ & - & - & - & - \\
\hline 3 & $\begin{array}{l}\text { Laser } \\
\text { photocoagulation of } \\
\text { focus of } \\
\text { endometrioid } \\
\text { heterotopia of } \\
\text { vesicouterine pouch }\end{array}$ & $3 \%$ & $(9,09 \pm 5,00)$ & - & - & $1 \%$ & $(2,56 \pm 2,53)$ \\
\hline 4 & $\begin{array}{l}\text { Laser } \\
\text { photocoagulation of } \\
\text { focus of } \\
\text { endometrioid } \\
\text { heterotopia of } \\
\text { sacrouterine } \\
\text { ligaments }\end{array}$ & $5 \%$ & $(15,15 \pm 6,24)$ & $1 \%$ & $(3,85 \pm 3,77)$ & $1 \%$ & $(2,56 \pm 2,53)$ \\
\hline 5 & $\begin{array}{l}\text { Excision of } \\
\text { endometrioid } \\
\text { heterotopia on } \\
\text { ovarian surface }\end{array}$ & $4 \%$ & $(12,12 \pm 5,68)$ & - & - & - & - \\
\hline 5 & $\begin{array}{l}\text { Conservative } \\
\text { myomectomy }\end{array}$ & $1 \%$ & $(3,03 \pm 2,98)$ & $24 \%$ & $(92,31 \pm 5,23)$ & - & - \\
\hline 6 & $\begin{array}{l}\text { Abstaining from } \\
\text { conservative } \\
\text { myomectomy }\end{array}$ & - & - & $2 \%$ & $(7,69 \pm 5,23)$ & - & - \\
\hline 7 & Cystectomy & $18 \%$ & & $1 \%$ & $(3,85 \pm 3,77)$ & $2 \%$ & $(5,13 \pm 3,53)$ \\
\hline 8 & Adhesiolysis & $3 \%$ & $(9,09 \pm 5,00)$ & $3 \%$ & $(11,5 \overline{4} \pm 6,27)$ & $3 \%$ & $(7,69 \pm 4,27)$ \\
\hline 9 & Salpingoovariolisis & $2 \%$ & $(6,06 \pm 4,15)$ & $3 \%$ & $(11,54 \pm 6,27)$ & $10 \%$ & $(25,64 \pm 6,99)$ \\
\hline 10 & Salpingoneostomiya & $2 \%$ & $(6,06 \pm 4,15)$ & $2 \%$ & $(7,69 \pm 5,23)$ & $5 \%$ & $(12,82 \pm 5,35)$ \\
\hline 11 & Fimbrioplasty & $1 \%$ & $(3,03 \pm 2,98)$ & $1 \%$ & $(3,85 \pm 3,77)$ & $1 \%$ & $(2,56 \pm 2,53)$ \\
\hline 12 & Unilateral tubectomy & - & - & $2 \%$ & $(7,69 \pm 5,23)$ & $4 \%$ & $(10,2 \overline{6} \pm 4,86)$ \\
\hline 13 & Bilateral tubectomy & $1 \%$ & $(3,03 \pm 2,98)$ & $3 \%$ & $(11,54 \pm 6,27)$ & - & - \\
\hline
\end{tabular}


The analysis of obtained data has shown that according to data of three groups during comparison by one-way ANOVA was equal by Bonferroni $p=1,0$; Scheffe $p=0,93$; Tukey $\mathrm{p}=0,92$, at $(\mathrm{p}<0,05)$, that demonstrates that there are no significant differences between the groups.

\section{Discussion}

During the laparoscopic examination of fallopian tube the changes in 1 group are observed in $10 \%(30,30 \pm 8,00)$ of patients. The peritubal adhesions in $5 \%(15,15 \pm 6,24)$, changes of tube by hydrosalpynx and beading type in $1 \%(3,03 \pm 2,98)$ were visible the most frequently, attributes tube in endometriodic heterotropy are observed in $2 \%(6,06 \pm 4,15)$, tube change by «beading» type + peritubal adhesions in $1 \%(3,03 \pm 2,98)$.

In 2 group the changes are observed in $20 \%(76,92 \pm 8,26)$ of cases. The most frequently the tube

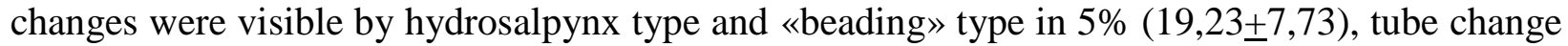
by «nodose salpingitis» type in $4 \%(15,38 \pm 7,08)$, tube change by peritubal adhesions type in $3 \%$ $(11,54 \underline{+6}, 27)$.

The similar tube change has occurred by nodose salpingitis+ hydrosalpynx tube type, by «beading» + peritubal adhesions and tube peritubal adhesions + hydrosalpynx tube type in $1 \%$ $(3,03 \pm 2,98)$ of cases.

In 3 group the changes are observed in $32 \%(82,05 \pm 6,15)$ of cases. The peritubal adhesions in $14 \%(35,90 \pm 7,68)$ were visible the most frequently, tube changes by hydrosalpynx type and «nodose salpingitis» type equally in $4 \%(10,26 \pm 4,86)$, injected tube attributes and by «beading» type in $3 \%(7,69 \pm 4,27)$.

Also the similar tube change was occurred by type tube nodose salpingitis+ tube hydrosalpynx and tube peritubal adhesions + tube hydrosalpynx in $2 \%(5,13 \pm 3,53)$, tube changes by «beading» type + tube by peritubal adhesions in $3 \%(7,69 \pm 4,27)$ of cases.

During comparison of three groups for change of fallopian tube it was detected that in 3 group the peritubal adhesions are in $14 \%(35,90 \pm 7,68)$ cases larger than in other groups despite the double-sided uterine tubes patency $(74,36 \%)$.

\section{Findings}

In such a manner in all three analyzable groups the majority of cases have turned to be comparable. In view of the presence of patients with natural sterility combined with reproductive diseases the frequency of fallopian tube abnormality in three groups was equal from $30 \%$ to $82,05 \%$, despite its double-sided uterine tubes patency from $74,36 \%$ to $84,85 \%$.

Therefore the precise diagnosis establishing is possible with correct observation of algorithm for examination of patients with natural sterility combined with reproductive diseases including the careful examination of complaints, anamnesis, data of special pelvic examination, ultrasound investigation and HSG. 
In particular, in first stage we recommend the uterotubography since the indolence, swiftness, simplicity and low cost are undeniable advantages of this method. Thus according to results of own clinical study we deduce that the application of ultrasound investigation combined with HSG ensures $95-100 \%$ of accuracy in determination of nature of fallopian tube affect in sterility. Therefore the endoscopic interventions shall be performed not with the purpose of diagnosis verification but with medical purpose.

\section{References}

[1] Kulakov V. I. Sterile marriage. Modern approaches to diagnosis and treatment: guide for doctors // Ed. Kulakov V. I. - M.: «GEOTAR-Media», 2006; 616 p.

[2] WHO. Global prevalence of infertility, infecundity and childlessness // 2014 March 28.

[3] Korsak V. S. The register of the ART centers of Russia. Report for the year 2009 // Problems of reproductions, 2012; 1: 8-16.

[4] Kayupova N. A., Mamedaliyeva N. M. Actual problems of reproductive medicine in Kazakhstan // Proceedings of the International Congress of obstetricians-gynecologists. Almaty; 1999; 6-7.

[5] Chachamovich J. R., Chachamovich E, Ezer H. e.a. Investigating quality of life and health-related quality of life in infertility: a systematic review // J. Psychosom. Obstet. Gynaecol. 2010; 31 (2):101-110.

[6] Kulakov V. I., Margiani F. A., Nazarenko T. A. The structure of female infertility and prognosis of reproductive function restoration using modern endoscopic methods // Obstetrics and gynecology. 2001; 3: 33-36.

[7] Kulakov V. I., Korneeva I. E. Modern approaches to diagnosis and treatment of female infertility // Obstetrics and gynecology. 2002; 2:56-59.

[8] Uskova M. A., Kuzmichev L. N. Rational approaches to the treatment of tubal-peritoneal infertility (review of the literature) // Problems of reproduction. Moscow, 2009; 4:24-27.

[9] Goncharova N. N., Adamyan L. V., Martyshkina E. Yu. et al. The structure of infertility in a married couple // New technologies in the diagnosis and treatment of gynecological diseases: Proceedings of the XXV International Congress with the course of endoscopy, M., 2012; $116 \mathrm{p}$.

[10] ESHRE Capri Workshop Group. Diagnosis and management of the infertile couple: missing information // Hum Reprod Update. 2004; 13:295-307.

[11] Kira E. F. Evolution of reproductive surgery in gynecology // Obstetrics and gynecology. 2007; 5:59-62.

[12] Yakovleva N. V. Surgical treatment of tubal-peritoneal infertility: problems and solutions // Bulletin of New Medical Technologies.2014; 21 (1):126 p.

[13] Avramenko N. V. Inflammatory diseases of the pelvic organs in women as a leading factor in the formation of tubal-peritoneal infertility // Zaporozhian Medical Journal.2014; 4:63-68.

[14] Manukhin I. B., Petrovich E. A. Innovative approach to the treatment of tubal-peritoneal infertility // Gynecology. Moscow, 2010; 3:15-20.

[15] Kuchuhidze S. T. Clinical evaluation of air-plasma flow with the generation of nitrogen monoxide during laparoscopic operations on the uterus and its appendages. Dis.. Candidate of Medical sciences. M; MSU; 2004; 176 p.

*Corresponding author.

E-mail address: asemz@ mail.ru/dr.smaylova@mail.ru/dinarakenzhetaevna@mail.ru 